\title{
Quality of Life and Associated Factors Among Patients with Epilepsy Attending Outpatient Department of Saint Amanuel Mental Specialized Hospital, Addis Ababa, Ethiopia, 2019
}

This article was published in the following Dove Press journal:

Journal of Multidisciplinary Healthcare

\author{
Gebremeskel Mesafint ${ }^{1}$ \\ Shegaye Shumet $\mathbb{D}^{2}$ \\ Yodit Habtamu (D) $^{3}$ \\ Tolesa Fanta $\left(\mathbb{D}^{3}\right)^{3}$ \\ Gebeyaw Molla $\mathbb{D}^{4}$ \\ 'Department of Nursing, Mizan-Tapi \\ University, Mizan-Aman, Ethiopia; \\ 2Department of Psychiatry, University of \\ Gondar, Gondar, Ethiopia; ${ }^{3}$ Department \\ of Psychiatry, Saint Amanuel Mental \\ Specialized Hospital, Addis Ababa, \\ Ethiopia; ${ }^{4}$ Department of Psychiatry, \\ Aksum University, Aksum, Ethiopia
}

\begin{abstract}
Background: Epilepsy is strongly associated with an impaired quality of life. Patients suffering from epilepsy have a poorer quality of life than both the general population and many other chronic disease sufferers. However, attention is not given on the quality of life of people with epilepsy other than focusing on symptom reduction. This increases the frequency of seizures, impacts on the ability to perform and increases health-related costs. The aim of this study was to assess quality of life and associated factors among patients with epilepsy attending the outpatient department of Amanuel Mental Specialized Hospital, Addis Ababa, Ethiopia.
\end{abstract}

Methods: An institution-based cross-sectional study design was conducted between May and June 2019 at Amanuel Mental Specialized Hospital. A systematic random sampling technique was used to get a total number of 447 samples. Data on quality of life was assessed through interviews using the World Health Organization Quality of Life-Brief (WHOQOLBREF) Version. The collected data were coded, entered into EpiData 3.1, and analyzed by using SPSS version 20. Simple and multiple linear regression analysis models were fitted and the unstandardized $\beta$ coefficient at $95 \%$ confidence interval was employed. The statistical significance was accepted at $p$-value $<0.05$.

Results: The mean score of quality of life was $61.1 \pm 11.6$ (95\%CI: 59.05, 61.23). Perceived stigma ( $\beta=-2.13,95 \% \mathrm{CI}:-2.96,-1.30)$, frequent seizure $(\beta=-3.16,95 \% \mathrm{CI}:-4.27,-2.04)$, AED adherence $(\beta=1.24,95 \% \mathrm{CI}: 1.10,1.30)$, antiepileptic drug side effect $(\beta=-0.32,95 \% \mathrm{CI}:-0.38$, $-0.26)$, anxiety ( $\beta-1.91,95 \% \mathrm{CI}:-2.95,-0.86)$, depression $(\beta=-3.59,95 \% \mathrm{CI}:-4.67,-2.52)$, poor social support $(\beta=-2.51,95 \% \mathrm{CI}:-3.62,-1.40)$ and moderate social support $(\beta=-1.60,95 \% \mathrm{CI}$ : $2.58,-0.62)$ were significantly associated factors with quality of life.

Conclusion: The finding from this study indicated that quality of life of patients with epilepsy were moderate. Perceived stigma, frequent seizure, comorbid depression and anxiety, antiepileptic drug nonadherence, antiepileptic drug side effect and poor social support were the predictors of quality of life.

Keywords: epilepsy, quality of life, WHOQOL-BREF

\section{Introduction}

Epilepsy is a common neurological disorder characterized by recurrent episodes of unprovoked seizures with or without loss of consciousness. ${ }^{1}$ It affects approximately 69 million people worldwide. The majority, 90\% lives in resource-poor countries. $^{2}$ It has a wide global distribution with high prevalence in the developing
Correspondence: Gebremeskel Mesafint Department of Nursing, Mizan-Tapi University, Mizan-Aman 260, Ethiopia Tel +251918209867

Email mulegeta III@gmail.com
Journal of Multidisciplinary Healthcare 2020:13 2021-2030

2021 
world such as in sub-Saharan African countries. ${ }^{3}$ In Ethiopia, epilepsy is a public health problem, with an estimated prevalence of the disease in the country reported to be 5.2/1000 inhabitants at risk with the annual incidence of 64 in100,000 inhabitants in large scale, rural and community based studies. ${ }^{4,5}$

Epilepsy can be associated with a considerable physical and emotional impact on a person's quality of life. The impact can be greater than that of many other chronic diseases. These impacts lead to limitation in employment, independence and social activities. ${ }^{6}$ People with epilepsy may fear to go outside their homes unaccompanied. They may fear what other people may think of them if they have a seizure in public. All over the world throughout history, epilepsy has been a culturally devalued condition. This devaluing often leads to stigma and psychosocial burden. In most parts of the world, epilepsy is believed to be contagious and possession by the devil and ancestral spirits. $^{7}$ They experience different psychosocial challenges at different level of health system. It has an enormous impact on quality of life and lowering income compared with other people with chronic illness. ${ }^{8,9}$

Quality of life is defined by the World Health Organization (WHO) as individuals' perceptions of their position in life in the context of the culture and value systems in which they live and in relation to their goals, expectations, standards, and concerns. ${ }^{10}$ It is a broad concept incorporating in a complex way subjective assessment of his or her physical health, psychological state, level of independence, social relationships, personal beliefs and their relationships to their environment. ${ }^{11}$ The scope of quality of life extends beyond traditional symptom reduction and includes the patient's subjective feeling of wellbeing, satisfaction, functioning and impairment. ${ }^{12}$ Epilepsy affects many aspects of quality of life, including social functioning, the ability to concentrate on things, the ability to work with full potential, psychological aspect, and other daily activity. ${ }^{1}$ In some situations, perceived stigma and its impact on quality of life may pose a bigger challenge than the clinical severity. The incorporation of quality-of-life measurements into the assessment of treatment outcomes is a critical concept in health care today, and reflects a shift away from sole reliance on physical signs and diagnostic studies. ${ }^{13}$

Quality of life among people with epilepsy is significantly affected by several clinical and demographic factors such as being female, younger age, being single and divorced, education status and unemployment, early age of onset, seizure frequency, perceive stigma, lack of social support, comorbidity, AED nonadherence, antiepileptic drug side effect, and substance abuse have been shown as the major contributing factors on QOL of people with epilepsy. ${ }^{9,14-17}$

Evaluation of the impact of epilepsy on quality of life would throw light on various factors that affect quality of life in such a population. There is a growing consensus that successful treatment should not only target symptom severity, but also impairment in functioning and QOL in leading to restoration of health. ${ }^{18,19}$ However, guidelines have a considerable focus only on pharmacotherapy for symptomatic recovery ${ }^{20}$ and the majority of clinical and research efforts in this area have been more attentive to the impact of interventions on symptom reduction than on well-being or QOL. ${ }^{21}$ In developing countries, there is a scarcity of established evidence for quantifying the impact of epilepsy on quality of life. The issue of assessing quality of life and the factors contributing is highly overlooked among patient with epilepsy in Ethiopia. Therefore, the aim of this study was to assess quality of life and associated factors among patients with epilepsy, and the results of this study will add an input to policy makers to scale up a public health program for designing and implementing strategies to improve quality of life.

\section{Objective}

This aim of this study is to assess quality of life and associated factors among patients with epilepsy attending outpatient department of Saint Amanuel Mental Specialized Hospital, Addis Ababa, Ethiopia.

\section{Study Setting and Population}

An institution-based cross-sectional study was conducted among patients with epilepsy at Saint Amanuel Mental Specialized Hospital, Addis Ababa, Ethiopia, in May and June 2019. Addis Ababa, the capital of Ethiopia, had a total of 608 health facilities (hospitals, health centers, and private clinics) serving more than three million inhabitants. Saint Amanuel Mental Specialized Hospital (AMSH) is the only specialized mental hospital in the city. It is administered under the Federal Ministry of Health and provides mental health service for patients coming from the entire nation. The hospital has a total of 300 beds and 18 outpatient departments that serve patients with psychiatric disorders, of these three OPDs serve patients with epilepsy. In 2019, around 14,388 patients with epilepsy visited the outpatients department for 
follow-up in the six months from September to February. On average 2398 patients with epilepsy visited the hospital, in one month.

\section{Participants}

The participants of this study were epileptic patients receiving follow-up care at AMSH, Addis Ababa, Ethiopia. The single population mean formula with the assumptions of $56.36 \pm 13.37$ mean and standard deviation of the overall quality of life of a study conducted in Ethiopia, ${ }^{14} 1.96$ $\mathrm{Z}$ (standard normal distribution), 95\%CI, $\alpha=0.05$, and a $10 \%$ nonresponse rate. The calculated sample size yielded 447. The average number of patients was calculated with their monthly visit in mind. Participants were selected for interviews using the systematic random sampling technique.

\section{Inclusion and Exclusion Criteria}

All patients with epilepsy who had six months and above follow-ups at the neurologic clinic and who were $\geq 18$ years of age were included, whereas participants with intellectual disability were excluded.

\section{Measurement}

Quality of life was measured using World Health Organization Quality of Life-Brief (WHOQOL-BREF). The WHOQOL-BREF was developed by the WHOQOL group with 4500 respondents in 15 international field centers, which is a cross-culturally validated tool and used to assess the patients' quality of life. The WHOQOLBREF includes 26 items measuring the following domains: physical health, psychological health, social relationships, and environment. Two further items evaluate the individual's overall perception of quality of life and the individual's overall perception of their health. Domain scores are scaled in a positive direction (ie, higher scores correspond to better quality of life). QOL raw scores are transformed into a range of $0-100$. The overall quality of life was computed as the average of the score of the four domains. The higher mean score indicates better the quality of life and vice versa.

Social support was measured by the Oslo Social Support Scale. The scale ranged from 3-14, and the scores 3-8, 9-11, and 12-14 stood for "poor", "moderate", and "strong" social support, respectively. ${ }^{22}$

Anxiety and depression symptoms were measured using the Hospital Anxiety and Depression Scale (HADS). It has 14 items and two subscales. Anxiety subscale (HADS-A) and depression subscale (HADS-D). There are seven items measuring cognitive and emotional aspects of depressive symptoms, and the other seven items were focusing on cognitive and emotional aspects of anxiety. HADS was a reliable and valid instrument in Ethiopia. ${ }^{23}$ Patients who scored $\geq 8$ for both anxiety and depression symptoms were considered as having depression and anxiety.

Perceived stigma was measured by using a three-item Jacoby perceived stigma scale, which was developed originally for another neurological condition, stroke, for which it was shown to have good psychometric properties and was subsequently adapted for epilepsy. Each of the three items requires a simple yes/no response. ${ }^{24}$

AED adherence was measured by the Medication Adherence Reporting Scale-5 (MARS-5). The MARS-5, a self-reported instrument containing five items regarding medication adherence. Each item was rated on a five-point Likert scale and the range of the MARS-5 total score was between 5 and 25. A higher score on the MARS-5 represents a better medication adherence. ${ }^{25}$

The Liverpool Adverse Events Profile (LAEP) was used to assess AED side effects. It was developed in the 1990s by the Liverpool group and the LAEP was used to assess the frequency of AED side effects during the last four weeks. It has 19 items rated on a four-point Likert scale with (1) "never a problem" to (4) "always a problem" and the total scores range from 19 to 76 , with the higher score indicating more frequent symptoms reporting. ${ }^{26}$ Substance-related factors were assessed by ASSIST which is a brief screening questionnaire developed by WHO. This tool was used to assess the current psychoactive substance use of the participants. $^{27}$

Items on sociodemographic factors (age, sex, ethnicity, religion, marital status, educational status, and occupational status) were adopted from a variety of literature.

\section{Data Collection Technique}

To assure the quality of data high emphasis was given to designing the data collection instrument for its simplicity. The pretest was done on 5\% (23) of the samples, on patients with epilepsy five days prior to the data collection at St Paul's Millennium Medical College Hospital. The questionnaire was checked for clarity, simplicity, and understandability. The reliability test was done on the scale to assess the quality of life and the Cronbach's alpha was 0.85 . Data collectors were trained on an introduction to epilepsy, quality of life, research methods, 
interviewing skills, sampling, recruitment, and the ethical aspects of the research.

Furthermore, they were made aware of ethical principles, such as confidentiality/anonymity/and securing respondents' informed consent for participation. Data were collected by three BSc psychiatry nurses and regularly supervised by one senior master psychiatry professor. The collected data were reviewed and check for completeness and relevance by the principal investigator each day.

\section{Data Processing and Analysis}

The collected data were coded, entered in to EpiData version 3.1 and analyzed by using SPSS version 20 . Descriptive statistics (frequency, percent, mean and standard deviation) were used to summarize data and evaluate the distribution of responses. Assumption tests were checked. In simple linear regression, variables with $p$-value $<0.20$ were entered into multiple linear regression to overcome confounding variables. The multiple coefficient of determination $\left(\mathrm{R}^{2}\right)$ was used for the model fitness. The result was expressed as unstandardized $\beta$ coefficient with $95 \%$ confidence level and $p$-value $<0.05$ was considered statistically significant.

\section{Ethical Approval and Consent to Participate}

Ethical approval and clearance were obtained from the Joint Ethical Review Committee of the University of Gondar and AMSH. A formal letter of permission was obtained from AMSH. Written informed consent was obtained from each study participants after explaining the purpose and benefit of the study. This study was conducted in accordance with the Declaration of Helsinki. The participants were informed that they have the right to refuse participation in the study at any time and refusing to participate will not affect them. The study subjects were assured confidentiality as the information they give will not be used for any purpose other than for the study.

\section{Results}

A total of 439 participants took part with a response rate of $98.2 \%$. The mean age of the participants was $34( \pm \mathrm{SD}=10)$ years; more than half (64.7\%), of were male; $231(52.6 \%)$ were not married; $129(29.4 \%)$ had secondary school education; $273(62.2 \%)$ were Orthodox Christian, and 146 (33.3\%) were Amhara by ethnicity. Regarding occupation, $182(41.5 \%)$ of the participants were unemployed (Table 1).

\section{Clinical Factors of the Respondents}

The mean age for the onset of epilepsy was $19( \pm \mathrm{SD}=10)$ years. Regarding the duration of the illness, 272 (62\%) had 11 and above years. The majority of the participants, 307 (69.9\%) were under monotherapy, and 165 (37.6\%) had one or more seizure attack per month. The mean (SD) AED adherence and having AED adverse effects were 16 \pm 3 and $36 \pm 9$, respectively. Of the respondents, 158 (36\%), and $155(35.3 \%)$ had depression and anxiety symptoms, respectively. About 55 (12.5\%) of the participants had additional diagnosis of medical illness (Table 2).

Table I Sociodemographic Characteristics of Patients with Epilepsy on Follow-up at Amanuel Mental Specialized Hospital, Addis Ababa, Ethiopia, 2019 ( $N=439)$

\begin{tabular}{|c|c|c|c|}
\hline Variables & Categories & Frequency & Percentage \\
\hline Age (mean $\pm S D$ ) & $34.62 \pm 10.37$ & & \\
\hline \multirow[t]{2}{*}{ Sex } & Male & 284 & 64.7 \\
\hline & Female & 155 & 35.3 \\
\hline \multirow[t]{4}{*}{ Religion } & Orthodox & 273 & 62.2 \\
\hline & Muslim & 101 & 23 \\
\hline & Protestant & 53 & 12.1 \\
\hline & Others ${ }^{\mathrm{a}}$ & 12 & 2.7 \\
\hline \multirow[t]{5}{*}{ Ethnicity } & Amhara & 146 & 33.3 \\
\hline & Oromo & 134 & 30.5 \\
\hline & Tigre & 20 & 4.6 \\
\hline & Gurage & 116 & 26.4 \\
\hline & Others ${ }^{b}$ & 23 & 5.2 \\
\hline \multirow[t]{3}{*}{ Marital status } & Single & 231 & 52.6 \\
\hline & Married & 163 & 37.1 \\
\hline & $\begin{array}{l}\text { Divorced/ } \\
\text { widowed }\end{array}$ & 45 & 10.3 \\
\hline \multirow[t]{4}{*}{$\begin{array}{l}\text { Educational } \\
\text { status }\end{array}$} & $\begin{array}{l}\text { No formal } \\
\text { education }\end{array}$ & & \\
\hline & Primary & 126 & 28.7 \\
\hline & Secondary & 129 & 29.4 \\
\hline & $\begin{array}{l}\text { Tertiary and } \\
\text { above }\end{array}$ & 90 & 20.5 \\
\hline \multirow{4}{*}{$\begin{array}{l}\text { Occupational } \\
\text { status }\end{array}$} & Employed & 114 & 25.9 \\
\hline & Private business & 122 & 27.8 \\
\hline & Unemployed & 182 & 41.5 \\
\hline & Others ${ }^{c}$ & 21 & 4.8 \\
\hline
\end{tabular}

Notes: a'Catholic, Wakefeta, Hawariyat. ${ }^{\text {b }} \mathrm{Hadia}$, Wolayta, Gamo, Afar. ${ }^{\mathrm{C} H o u s e w i f e, ~}$ student. 
Table 2 Description of Clinical Characteristics of Patients with Epilepsy at Amanuel Mental Specialized Hospital, Addis Ababa, Ethiopia, $2019(\mathrm{~N}=439)$

\begin{tabular}{|c|c|c|c|}
\hline Variables & Category & Frequency & $\begin{array}{l}\text { Percentage/ } \\
\text { Mean }\end{array}$ \\
\hline $\begin{array}{l}\text { Age of onset } \\
\text { (mean } \pm S D)\end{array}$ & & & $19.73 \pm 10.42$ \\
\hline $\begin{array}{l}\text { Medication } \\
\text { adherence } \\
(\text { mean } \pm S D)\end{array}$ & & & $16.37 \pm 3.76$ \\
\hline $\begin{array}{l}\text { Side effect of AED } \\
\text { (mean } \pm S D)\end{array}$ & & & $36.67 \pm 9.47$ \\
\hline Duration of illness & $\begin{array}{l}\leq 5 \text { years } \\
6-10 \text { years } \\
\geq 11 \text { years }\end{array}$ & $\begin{array}{l}75 \\
92 \\
272\end{array}$ & $\begin{array}{l}17 \\
21 \\
62\end{array}$ \\
\hline $\begin{array}{l}\text { Presence of seizure } \\
\text { per month }\end{array}$ & $\begin{array}{l}\text { Absence } \\
\text { Present }\end{array}$ & $\begin{array}{l}274 \\
165\end{array}$ & $\begin{array}{l}62.4 \\
37.6\end{array}$ \\
\hline Drug therapy & $\begin{array}{l}\text { Monotherapy } \\
\text { Polytherapy }\end{array}$ & $\begin{array}{l}307 \\
132\end{array}$ & $\begin{array}{l}69.9 \\
30.1\end{array}$ \\
\hline Depression & $\begin{array}{l}\text { Yes } \\
\text { No }\end{array}$ & $\begin{array}{l}158 \\
281\end{array}$ & $\begin{array}{l}36 \\
64\end{array}$ \\
\hline Anxiety & $\begin{array}{l}\text { Yes } \\
\text { No }\end{array}$ & $\begin{array}{l}155 \\
284\end{array}$ & $\begin{array}{l}35.3 \\
64.7\end{array}$ \\
\hline $\begin{array}{l}\text { Comorbid medical } \\
\text { diagnosis }^{\mathrm{a}}\end{array}$ & $\begin{array}{l}\text { Yes } \\
\text { No }\end{array}$ & $\begin{array}{l}55 \\
384\end{array}$ & $\begin{array}{l}12.5 \\
87.5\end{array}$ \\
\hline
\end{tabular}

Notes: ${ }^{a}$ Diabetes mellitus, HIVIAIDS, hypertension and congestive heart failure.

\section{Psychosocial and Substance-related Characteristics of Respondents}

Regarding psychosocial characteristics of the participants, 203 (46.2\%) had poor social support; 227 (51.7\%) had perceived stigma (Table 3). About 135 (30.8\%) of the participants were using substance user for a nonmedical purpose at the moment (Figure 1).

\section{Mean Quality of Life Score of Participants}

The overall mean (SD) score of quality of life among epilepsy patients was $60 \pm 11$ with $(95 \% \mathrm{CI}$ : $59.05,61.23)$. Among four domains of WHO QOL-BREF, participants scored highest in the physical domain $(61 \pm 15)$, while the lowest mean (SD) score was for environment domain (57 \pm 15 ) (Table 4).

\section{Factors Associated with Quality of Life}

Simple linear regression was carried out in relation to a number of variables which could conceivably be
Table 3 Description of Psychosocial and Substance Related Characteristics of Respondents Among Patients with Epilepsy at Amanuel Mental Specialized Hospital, Addis Ababa, Ethiopia, $2019(\mathrm{~N}=439)$

\begin{tabular}{|l|l|l|l|}
\hline Variables & Categories & Frequency & Percentage \\
\hline Social support & Poor & 203 & 46.2 \\
& Moderate & 120 & 27.4 \\
& Strong & 116 & 26.4 \\
\hline \multirow{2}{*}{ Perceived stigma } & Stigmatized & 227 & 51.7 \\
& Nonstigmatized & 212 & 48.3 \\
\hline
\end{tabular}

expected to influence quality of life. Variables with $p$-value $<0.20$ during simple linear regression analysis were selected for further analysis in multiple linear regression analysis. Duration of illness, seizure frequency, comorbid medical diagnosis, perceived stigma, level of education, marital status, occupation status, AED adherence, social support, number of antiepileptic drugs, antiepileptic drug side effect, comorbid depression and anxiety were factors associated with quality of life.

The results of multiple linear regression showed that AED side effects, AED adherence, seizure frequency, perceived stigma, depression, anxiety, and poor social support were found to be statistically significant at $p$-value $<0.05$. Based on multiple linear regression $89 \%$ of the variation of quality of life was explained by variables in the model.

A score in quality of life decreased by 0.32 for every unit increase in a score of AED side effects with $(\beta=-0.3295 \% \mathrm{CI}$ : $-0.38,-0.26$ ). A score in quality of life increase by 1.24 for every unit increase in a score of AED adherence with $(\beta=1.24$, $95 \% \mathrm{CI}: 1.10,1.30)$. A score in quality of life decreased by 3.16 in every one month seizure attack $(\beta=-3.16,95 \% \mathrm{CI}$ : $-4.27,-2.04)$. Quality of life of epileptic patients decreased by $1.91,3.59$ in every unit increase in a score of anxiety and depressive symptoms $(\beta=-1.91,95 \% \mathrm{CI}:-2.95,-0.86),(\beta=$ $-3.59,95 \% \mathrm{CI}:-4.67,-2.52)$ respectively. In every unit experience of perceived stigma quality of life reduce by 2.13 $(\beta=-2.13,95 \% \mathrm{CI}:-2.96,-1.30)$. Individuals with poor social support have decreased quality of life by $2.51(\beta=-2.51,95 \%$ CI: $-3.62,-1.40)$ and those with moderate social support quality of life is reduced by $1.60(\beta=-1.60,95 \% \mathrm{CI}:-2.58$, -0.62 ) compared with strong social support (Table 5).

\section{Discussion}

This study tried to assess quality of life and associated factors among patients with epilepsy. According to this 


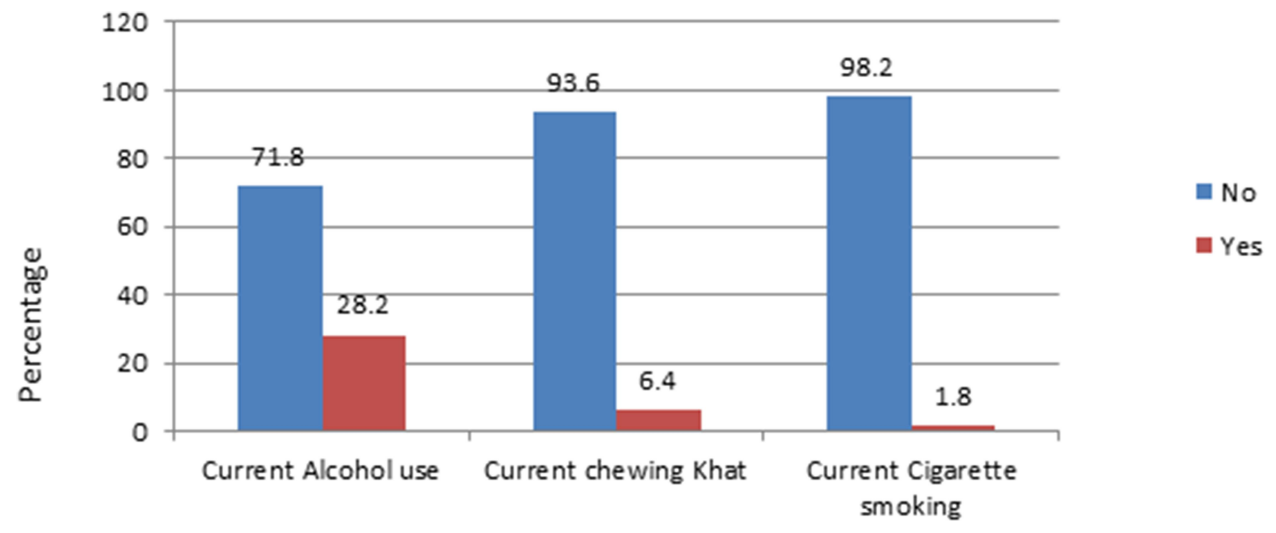

Figure I Percentage of current substance user among patients with epilepsy at Amanuel Mental Specialized Hospital, Addis Ababa, Ethiopia, 2019 ( $\mathrm{N}=439$ ).

finding, the mean quality of life score among participants was $60.14( \pm \mathrm{SD}=11.61)$. This result was in line with 61.49 mean score of Indian $^{28}$ and 58 mean score of Ugandan ${ }^{17}$ studies.

In the current study, we had a mean higher quality of life score in epileptic patients, compared to a study conducted in Kenya (mean score of 49.90), Bhutan (mean score of 48.9), and Poland (mean score of 55.18). ${ }^{29-31}$ The possible reason for this difference might be sample size difference, clinical characteristics of the participants, sociocultural difference and study setting. The sample size was higher in this study compared to the sample of Kenya, Bhutan, and Poland. In the Kenyan study the participants use of poly AED therapy was large (54\%) compared with this study (30\%). Different literature has shown ${ }^{31-33}$ polytherapy receiving patients had lower mean quality of life. More than half (69\%) of study participants in Poland had medical comorbidity compared with $12.5 \%$ in this study. This high comorbidity of medical illness might contribute to low mean quality of life.

However, this finding was lower than the mean score of other countries, like 74.9 in India, 70.64 in Serbia, 68.9 in Malaysia, 82 in Canada, and 66.0 in the UK. ${ }^{34-38}$ The possible reason for this better quality of life might be the availability of standard medical care, sociocultural belief and lifestyle of the patient compared with this study.

Regarding domains of quality of life, the environmental domain had low quality of life (mean score of 57.78). This result was supported by an Indian study, where the environmental domain of patients with epilepsy was mostly affected. ${ }^{39}$ In contrast, results from Ghana showed that the social domain score was the lowest mean score. ${ }^{40}$ The difference might be due to variation in belief, culture, and lifestyle factors which affects quality of life measures. Since quality of life is a subjective concept, they might perceive differently in people of different cultures.

Seizure frequency was significantly associated with quality of life. The probable explanation might be frequent seizure has been related to excess fear, feeling of stigmatization and limit their physical activity. This might lead to impairment in physical activity and psychological problems. This finding was consistent with other studies. ${ }^{35,36,39,41-43}$

Patients who had perceived stigma were negatively associated with quality of life. This result is supported by other study results, ${ }^{44}$ people with perceived stigma had a negative impact on quality of life even when seizures are controlled. In fact, people with epilepsy frequently experience rejection and isolation due to the commonly held misconception of

Table 4 Quality of Life Among Patients with Epilepsy at Amanuel Mental Specialized Hospital, Addis Ababa, Ethiopia, 2019 (N=439)

\begin{tabular}{|l|l|l|l|}
\hline Domain & Mean ISD & $\begin{array}{l}\text { Percent of Participants } \\
\text { Scored Below the Mean }\end{array}$ & $\mathbf{9 5 \% C l}$ \\
\hline Physical & $61.8 \pm 15.3$ & $51.5 \%$ & $(60.40,63.28)$ \\
Psychological & $60.1 \pm 12.8$ & $50.1 \%$ & $(58.95,61.35)$ \\
Social & $60.8 \pm 15.9$ & $54.2 \%$ & $(59.30,62.29)$ \\
Environmental & $57.7 \pm 14.7$ & $50.1 \%$ & $(56.40,59.17)$ \\
Overall & $60.1 \pm 11.6$ & $51.7 \%$ & $(59.05,61.23)$ \\
\hline
\end{tabular}


Table 5 Multiple Linear Regression of Quality of Life Among Patients with Epilepsy Attending at Amanuel Mental Specialized Hospital, Addis Ababa, Ethiopia, 2019

\begin{tabular}{|c|c|c|c|}
\hline \multicolumn{2}{|l|}{ Variable } & Crude $\beta(95 \% \mathrm{Cl})$ & Adjusted $\beta(95 \% \mathrm{Cl})$ \\
\hline \multicolumn{2}{|l|}{ Married } & Ref & Ref \\
\hline \multicolumn{2}{|l|}{ Single } & $-2.03(-4.20,0.14)$ & $-0.12(-0.96,0.72)$ \\
\hline \multicolumn{2}{|c|}{ Divorced/widowed } & $0.17(-3.41,3.77)$ & $0.21(-1.09,1.52)$ \\
\hline \multirow{3}{*}{\multicolumn{2}{|c|}{$\begin{array}{l}\text { Duration }<5 \text { years } \\
\text { Duration } 5-10 \text { years } \\
\text { Duration } \geq 11 \text { years }\end{array}$}} & Ref & Ref \\
\hline & & $1.39(-1.28,4.06)$ & $-0.48(-1.68,0.71)$ \\
\hline & & $-1.50(-3.74,0.73)$ & $-0.71(-1.76,0.33)$ \\
\hline \multicolumn{2}{|c|}{ No formal education } & $-5.22(-7.84,-2.61)$ & $0.22(-1.10,1.55)$ \\
\hline \multicolumn{2}{|c|}{ Primary } & $-0.36(-2.77,2.04)$ & $0.08(-1.21,1.05)$ \\
\hline \multicolumn{2}{|l|}{ Secondary } & $1.38-1.00,3.77)$ & $-0.16(-1.26,0.95)$ \\
\hline \multicolumn{2}{|c|}{ Tertiary and above } & Ref & Ref \\
\hline \multicolumn{2}{|l|}{ Employed } & Ref & Ref \\
\hline \multicolumn{2}{|l|}{ Private business } & $4.67(2.27,7.06)$ & $0.80(-0.23,1.85)$ \\
\hline \multicolumn{2}{|l|}{ Unemployed } & $-5.89(-8.03,-3.75)$ & $-0.42(-1.46,0.62)$ \\
\hline \multicolumn{2}{|l|}{ Others } & $2.01(-3.09,7.12)$ & $0.39(-1.45,2.25)$ \\
\hline \multicolumn{2}{|c|}{ Side effect of AED } & $-0.91(-0.99,-0.84)$ & $-0.32(-0.38,-0.26)^{*}$ \\
\hline \multicolumn{2}{|l|}{ AED adherence } & $2.60(2.45,2.76)$ & $1.24(1.10,1.30)^{*}$ \\
\hline Drug therapy & $\begin{array}{l}\text { One } \\
\geq 2\end{array}$ & $\begin{array}{l}\text { Ref } \\
-1.87(-4.24,0.50)\end{array}$ & $\begin{array}{l}\text { Ref } \\
-0.19(-1.04,0.64)\end{array}$ \\
\hline $\begin{array}{l}\text { Presence of } \\
\text { seizure per } \\
\text { month }\end{array}$ & $\begin{array}{l}\text { Yes } \\
\text { No }\end{array}$ & $\begin{array}{l}-17.88(-19.38,-16.38) \\
\text { Ref }\end{array}$ & $\begin{array}{l}-3.16(-4.27,-2.04)^{*} \\
\operatorname{Ref}\end{array}$ \\
\hline $\begin{array}{l}\text { Perceived } \\
\text { stigma }\end{array}$ & $\begin{array}{l}\text { Yes } \\
\text { No }\end{array}$ & $\begin{array}{l}-6.16(-7.67,-4.65) \\
\operatorname{Ref}\end{array}$ & $\begin{array}{l}-2.13(-2.96,-1.30)^{*} \\
\operatorname{Ref}\end{array}$ \\
\hline $\begin{array}{l}\text { Comorbid } \\
\text { medical illness }\end{array}$ & $\begin{array}{l}\text { Yes } \\
\text { No }\end{array}$ & $\begin{array}{l}-4.73(-7.99,-1.46) \\
\text { Ref }\end{array}$ & $\begin{array}{l}0.31(-0.8 \mathrm{I}, \mathrm{I} .44) \\
\text { Ref }\end{array}$ \\
\hline Depression & $\begin{array}{l}\text { Yes } \\
\text { No }\end{array}$ & $\begin{array}{l}-16.71(-18.35,-15.07) \\
\text { Ref }\end{array}$ & $\begin{array}{l}-3.59(-4.67,-2.52)^{* *} \\
\text { Ref }\end{array}$ \\
\hline Anxiety & $\begin{array}{l}\text { Yes } \\
\text { No }\end{array}$ & $\begin{array}{l}-15.80(-17.53,-14.06) \\
\operatorname{Ref}\end{array}$ & $\begin{array}{l}-1.91(-2.95,-0.86)^{*} \\
\text { Ref }\end{array}$ \\
\hline Social support & $\begin{array}{l}\text { Poor } \\
\text { Moderate } \\
\text { Strong }\end{array}$ & $\begin{array}{l}-14.53(-16.24,-12.82) \\
7.09(4.73,9.44) \\
\text { Ref }\end{array}$ & $\begin{array}{l}-2.51(-3.62,-1.40)^{*} \\
-1.60(-2.58,-0.62)^{* *} \\
\operatorname{Ref}\end{array}$ \\
\hline
\end{tabular}

Notes: ${ }^{*} p<0.001,{ }^{*} p<0.01$. Ref, reference, adjusted $R^{2}, 0.89$.

epilepsy. ${ }^{45}$ Perceived stigma was associated with increased stress, reduced psychological functioning and patient satisfaction which indirectly affect quality of life. This result is in agreement with other studies. ${ }^{29,32,35,40}$

Epileptic patients with comorbid depression were negatively associated with quality of life. This finding was similar to results from other studies..$^{32,35,46}$ This might be due to the exertion of depressed mood, hopelessness and loss of interest on a profound negative effect on quality of life. This might be also be due to the impact of depression on the patient's perception of illness, compliance with medication and use of health service. ${ }^{32}$ Screening for depression in patients with epilepsy has been recommended, ${ }^{47}$ but is still not routine. The study also revealed that patients with comorbid anxiety had a lower quality of life score. This result was supported by studies in Thailand and UK. ${ }^{35,48}$ Epileptic patients with frequent seizure had more common anxiety symptoms ${ }^{49}$ and such a mental health issue is not addressed, It would have a negative consequence to quality of life of patients.

The result of this study showed that AED nonadherence had negatively associated with quality of life. This finding was supported by results of study in $\mathrm{UK}^{35}$ and US. ${ }^{50}$ Nonadherent patients were more likely to have experienced greater life consequence as a result of seizure. ${ }^{50}$ The possible reason could be AED nonadherence leads to worse clinical outcomes and increased frequency of seizure, which in turn derives an impaired quality of life.

Poor social support was negatively associated with quality of life. The possible reason might be the feeling of being loved and wanted contributed to provide a supportive environment which help to cope with the illness. This finding was supported by another study in Switzerland. $^{51}$

AED side effects were negatively associated with quality of life. Having the side effects of AED emerged as the most important determinant of quality of life in China ${ }^{1}$ which is in agreement with this finding. The possible explanation might be the adverse effect of some AED on body weight and appearance, including hair loss, gingival hyperplasia, and polytrichia may cause a negative impact on their quality of life.

\section{Limitation of the Study}

Our cross-sectional design has prevented us from reporting the casual relationships of the associations we found. Because the data collection method was face-to-face interviews, patients might have given socially acceptable answers during the interviews, especially to substancerelated questions. In addition social desirability and recall bias might have been also the other limitations. The WHOQOL-BREF tool was developed for the person suffering from chronic disease including epilepsy, but not specific for patients with epilepsy. In our study, we did not observe the effect of income on quality of life.

\section{Conclusion and Recommendations}

This study revealed that the quality of life among patients with epilepsy was moderate. Perceived stigma, having a seizure in the last one month, comorbid depression and anxiety, AED 
adherence, AED side effects, and poor social support were the associated factors for quality of life. It is important that quality of life assessment should be included in the patient treatment protocol which addresses psychosocial challenges that help to improve quality of life. It is better to enhance providing clinical counseling on how to cope with psychological, environmental and social challenges to achieve better health outcome. Implementing interventions that focus on early detection of comorbid psychiatric illnesses, like depression and anxiety in patients with epilepsy should be of great concern for health-care providers.

\section{Abbreviations}

AED, antiepileptic drug; AMSH, Amanuel Mental Specialized Hospital; HADS, Hospital Anxiety and Depression Scale; HRQOL, health-related quality of life; MARS, Medication Adherence Rating Scale; OSSS, Oslo Social Support Scale; QOL, quality of life; WHOQOLBREF, World Health Organization Quality of Life-Brief Version.

\section{Data Sharing Statement}

All data included in the manuscript has been included in the form of tables. The nonidentified raw data generated and/or analyzed during the current study are not publicly available due to confidentiality issues but are available from the corresponding author on reasonable request through email address of mullegeta111@gmail.com.

\section{Ethical Approval and Consent to Participate}

Ethical approval and clearance were obtained from the Joint Ethical Review Committee of the University of Gondar and AMSH. A formal letter of permission was obtained from AMSH. Written informed consent was obtained from each study participants after explaining the purpose and benefit of the study. This study was conducted in accordance with the Declaration of Helsinki. The participants were informed that they have the right to refuse participation in the study at any time and refusing to participate will not affect them. The study subjects were assured confidentiality as the information they give will not be used for any purpose other than for the study.

\section{Consent for Publication}

Not applicable.

\section{Acknowledgment}

We would like express our deepest gratitude to University of Gondar College of Medicine and Health Science Department of Psychiatry and Saint Amanuel Mental Specialized Hospital for giving us the chance to do this paper. Finally, yet importantly, I thank the data collectors, supervisor, and study participantswithout whom the research would not be done.

\section{Author Contributions}

All authors made a significant contribution to the conception, study design, acquisition of data, analysis and interpretation. Furthermore, all authors took part in drafting, revising or critically reviewing the manuscript; gave final approval of the version to be published; have agreed on the journal to which the manuscript has been submitted; and agree to be accountable for all aspects of the works.

\section{Funding}

This study was funded by Saint Amanuel Mental Specialized Hospital.

\section{Disclosure}

The authors report no conflicts of interest in this work.

\section{References}

1. Yue L, Yu P-M, Zhao D-H, et al. Determinants of quality of life in people with epilepsy and their gender differences. Epilepsy Behav. 2011;22(4):692-696. doi:10.1016/j.yebeh.2011.08.022

2. Ngugi AK, Bottomley C, Kleinschmidt I, Sander JW, Newton CR. Estimation of the burden of active and life-time epilepsy: a metaanalytic approach. Epilepsia. 2010;51(5):883-890. doi:10.1111/ j.1528-1167.2009.02481.x

3. Ba-Diop A, Marin B, Druet-Cabanac M, Ngoungou EB, Newton CR, Preux P-M. Epidemiology, causes, and treatment of epilepsy in sub-Saharan Africa. Lancet Neurol. 2014;13(10):1029-1044. doi:10.1016/S1474-4422(14)70114-0

4. Tekle-Haimanot R, Abebe M, Gebre-Mariam A, et al. Communitybased study of neurological disorders in rural central Ethiopia. Neuroepidemiology. 1990;9(5):263-277. doi:10.1159/000110783

5. Tekle-Haimanot R, Forsgren L, Ekstedt J. Incidence of epilepsy in rural central Ethiopia. Epilepsia. 1997;38(5):541-546. doi:10.1111/ j.1528-1157.1997.tb01138.x

6. Dua T, De Boer HM, Prilipko LL, Saxena S. Epilepsy care in the world: results of an ILAE/IBE/WHO global campaign against epilepsy survey. Epilepsia. 2006;47(7):1225-1231. doi:10.1111/j.1528-1167. 2006.00595.x

7. Austin JK, Shafer PO, Deering JB. Epilepsy familiarity, knowledge, and perceptions of stigma: report from a survey of adolescents in the general population. Epilepsy Behav. 2002;3(4):368-375. doi:10.1016/ S1525-5050(02)00042-2

8. Wiebe S, Eliasziw M, Bellhouse DR, Fallahay C. Burden of epilepsy: the Ontario health survey. Can J Neurol Sci. 1999;26(4):263-270. doi:10.1017/S0317167100000354 
9. Keikelame MJ, Suliaman T, Hendriksz M, Swartz L. Psychosocial challenges affecting the quality of life in adults with epilepsy and their carers in Africa: a review of published evidence between 1994 and 2014. Afr J Prim Health Care Fam Med. 2017;9(1):1-5. doi:10.4102/phcfm.v9i1.1275

10. Group W. The World Health Organization quality of life assessment (WHOQOL): position paper from the World Health Organization. Soc Sci Med. 1995;41(10):1403-1409. doi:10.1016/0277-9536(95)00112-K

11. Ware J, John E, Gandek B. The SF-36 Health Survey: development and use in mental health research and the IQOLA project. Int J Ment Health. 1994;23(2):49-73. doi:10.1080/00207411.1994.11449283

12. Quilty LC, Van Ameringen M, Mancini C, Oakman J, Farvolden P. Quality of life and the anxiety disorders. J Anxiety Disord. 2003;17 (4):405-426. doi:10.1016/S0887-6185(02)00225-6

13. Devinsky O. The meaning of quality of life to patients with epilepsy. Epilepsy Behav. 2000;1(1):S18-S20. doi:10.1006/ebeh.2000.0041

14. Tegegne MT, Muluneh NY, Wochamo TT, Awoke AA, Mossie TB, Yesigat MA. Assessment of quality of life and associated factors among people with epilepsy attending at Amanuel Mental Specialized Hospital, Addis Ababa, Ethiopia. Sci J Public Health. 2014;2(5):378-383. doi:10.11648/j.sjph.20140205.12

15. Saadi A, Patenaude B, Nirola DK, et al. Corrigendum to" Quality of life in epilepsy in Bhutan"[Seizure 39 (2016) 44-48]. Seizure. 2016;42:14. doi:10.1016/j.seizure.2016.09.001

16. Akinsulore A, Adewuya A. Psychosocial aspects of epilepsy in Nigeria: a review. Afr J Psychiatry (Johannesbg). 2010;13(5).

17. Nabukenya AM, Matovu JK, Wabwire-Mangen F, Wanyenze RK, Makumbi F. Health-related quality of life in epilepsy patients receiving anti-epileptic drugs at National Referral Hospitals in Uganda: a cross-sectional study. Health Qual Life Outcomes. 2014;12(1):49. doi:10.1186/1477-7525-12-49

18. Zimmerman M, Mattia JI, Posternak MA. Are subjects in pharmacological treatment trials of depression representative of patients in routine clinical practice? Am J Psychiatry. 2002;159(3):469-473. doi:10.1176/appi.ajp.159.3.469

19. Angst J, Kupfer D, Rosenbaum J. Recovery from depression: risk or reality? Acta Psychiatr Scand. 1996;93(6):413-419. doi:10.1111/ j.1600-0447.1996.tb10671.x

20. Brown T, Summerbell C. Systematic review of school-based interventions that focus on changing dietary intake and physical activity levels to prevent childhood obesity: an update to the obesity guidance produced by the National Institute for Health and Clinical Excellence. Obes Rev. 2009;10(1):110-141. doi:10.1111/j.1467-789X.2008.00515.x

21. Bonicatto S, Dew M, Zaratiegui R, Lorenzo L, Pecina P. Adult outpatients with depression: worse quality of life than in other chronic medical diseases in Argentina. Soc Sci Med. 2001;52 (6):911-919. doi:10.1016/S0277-9536(00)00192-1

22. Dalgard O Social support-consequences for individual and society. Bilthoven, RIVM: EUPHIX, EUphact; 2009. Available from: http:// www.euphix.org $>$ EUphact $\backslash$ Determinantsofhealth $\backslash$ Environment ISocialsupport. Accessed November 23, 2020.

23. Ayalu AR, Mitchell A. Reliability and validity of the Ethiopian version of the Hospital Anxiety and Depression Scale (HADS) in HIV infected patients. PLoS One. 2011;6(1):e16049. doi:10.1371/ journal.pone.0016049

24. Jacoby A. Felt versus enacted stigma: a concept revisited: evidence from a study of people with epilepsy in remission. Soc Sci Med. 1994;38(2):269-274. doi:10.1016/0277-9536(94)90396-4

25. Lin C-Y, Ou H-T, Nikoobakht M, Broström A, Årestedt K, Pakpour AH. Validation of the 5-item medication adherence report scale in older stroke patients in Iran. J Cardiovasc Nurs. 2018;33 (6):536-543. doi:10.1097/JCN.0000000000000488

26. Panelli RJ, Kilpatrick C, Moore SM, Matkovic Z, D'souza WJ, O'brien TJ. The Liverpool Adverse Events Profile: relation to AED use and mood. Epilepsia. 2007;48(3):456-463. doi:10.1111/j.15281167.2006.00956.x
27. Saitz R, Palfai TP, Cheng DM, et al. Screening and brief intervention for drug use in primary care: the ASPIRE randomized clinical trial. JAMA. 2014;312(5):502-513. doi:10.1001/jama.2014.7862

28. Rakesh P, Ramesh R, Rachel P, Chanda R, Satish N, Mohan V. Quality of life among people with epilepsy: a cross-sectional study from rural southern India. Natl Med J India. 2012;25(25):261-264.

29. Saadi A, Patenaude B, Nirola DK, et al. Quality of life in epilepsy in Bhutan. Seizure. 2016;39:44-48. doi:10.1016/j.seizure.2016.05.001

30. Kinyanjui DW, Kathuku DM, Mburu JM. Quality of life among patients living with epilepsy attending the neurology clinic at Kenyatta National Hospital, Nairobi, Kenya: a comparative study. Health Qual Life Outcomes. 2013;11(1):98. doi:10.1186/1477-7525-11-98

31. Staniszewska A, Kurkowska-Jastrzębska I, Tarchalska-Kryńska B. Quality of life in patients with epilepsy. J Public Health Nurs Med Rescue. 2015;157(3):20-26.

32. Mosaku KS, Fatoye FO, Komolafe M, Lawal M, Ola BA. Quality of life and associated factors among adults with epilepsy in Nigeria. Int J Psychiatry Med. 2006;36(4):469-481. doi:10.2190/R80G-580X$\mathrm{X} 1 \mathrm{H} 2-6936$

33. Petruzzi A, Rigamonti A, Finocchiaro CY, et al. Psychological features and quality of life in 50 adult patients with epilepsy and their caregivers from the Lecco epilepsy center, Italy. Epilepsy Behav. 2017;71:13-16. doi:10.1016/j.yebeh.2017.03.024

34. Saadi A, Patenaude B, Mateen FJ. Quality of life in Epilepsy-31 inventory (QOLIE-31) scores: a global comparison. Epilepsy Behav. 2016;65:13-17. doi:10.1016/j.yebeh.2016.09.032

35. Ridsdale L, Wojewodka G, Robinson E, et al. Characteristics associated with quality of life among people with drug-resistant epilepsy. $J$ Neurol. 2017;264(6):1174-1184. doi:10.1007/s00415-017-8512-1

36. Norsa'adah B, Zainab J, Knight A. The quality of life of people with epilepsy at a tertiary referral centre in Malaysia. Health Qual Life Outcomes. 2013;11(1):143. doi:10.1186/1477-7525-11-143

37. Milovanović M, Martinović Ž, Tošković O. Determinants of quality of life in people with epilepsy in Serbia. Epilepsy Behav. 2014;31:160-166. doi:10.1016/j.yebeh.2013.12.015

38. George J, Kulkarni C, Sarma G. Antiepileptic drugs and quality of life in patients with epilepsy: a tertiary care hospital-based study. Value Health Reg. 2015;6:1-6. doi:10.1016/j.vhri.2014.07.009

39. Anu M, Suresh K, Basavanna P. A cross-sectional study of quality of life among subjects with epilepsy attending a tertiary care hospital. J Clin Diagn Res. 2016;10(12):OC13.

40. Kofie CD Quality of Life among Patients With Epilepsy Attending the Korle-Bu Teaching Hospital, University of Ghana; 2015.

41. Velez FF, Bond TC, Anastassopoulos KP, et al. Impact of seizure frequency reduction on health-related quality of life among clinical trial subjects with refractory partial-onset seizures: a pooled analysis of Phase III clinical trials of eslicarbazepine acetate. Epilepsy Behav. 2017;68:203-207. doi:10.1016/j.yebeh.2016.10.027

42. Rawlings GH, Brown I, Reuber M. Predictors of health-related quality of life in patients with epilepsy and psychogenic nonepileptic seizures. Epilepsy Behav. 2017;68:153-158. doi:10.1016/j. yebeh.2016.10.035

43. Piperidou C, Karlovasitou A, Triantafyllou N, et al. Association of demographic, clinical and treatment variables with quality of life of patients with epilepsy in Greece. Qual Life Res. 2008;17(7):987-996. doi:10.1007/s11136-008-9375-9

44. Fawale MB, Owolabi MO, Ogunniyi A. Effects of seizure severity and seizure freedom on the health-related quality of life of an African population of people with epilepsy. Epilepsy Behav. 2014;32:9-14.

45. Boling W, Means M, Fletcher A. Quality of life and stigma in epilepsy, perspectives from selected regions of Asia and Sub-Saharan Africa. Brain Sci. 2018;8(4):59. doi:10.3390/brainsci8040059

46. Jovel CAE, Salazar SR, Rodríguez CR, Mejía FES. Factors associated with quality of life in a low-income population with epilepsy. Epilepsy Res. 2016;127:168-174. doi:10.1016/j.eplepsyres.2016. 08.031 
47. Elliott JO, Richardson VE. The biopsychosocial model and quality of life in persons with active epilepsy. Epilepsy Behav. 2014;41:55-65. doi:10.1016/j.yebeh.2014.09.035

48. Phabphal K, Geater A, Limapichart K, Satirapunya P, Setthawatcharawanich S. Quality of life in epileptic patients in southern Thailand. Med J Med Assoc Thai. 2009;92(6):762.

49. Beyenburg S, Mitchell AJ, Schmidt D, Elger CE, Reuber M. Anxiety in patients with epilepsy: systematic review and suggestions for clinical management. Epilepsy Behav. 2005;7(2):161-171. doi:10. 1016/j.yebeh.2005.05.014
50. Hovinga CA, Asato MR, Manjunath R, et al. Association of non-adherence to antiepileptic drugs and seizures, quality of life, and productivity: survey of patients with epilepsy and physicians. Epilepsy Behav. 2008;13(2):316-322. doi:10.1016/j.yebeh.2008. 03.009

51. Mahrer-Imhof R, Jaggi S, Bonomo A, et al. Quality of life in adult patients with epilepsy and their family members. Seizure. 2013;22 (2):128-135. doi:10.1016/j.seizure.2012.11.012

\section{Publish your work in this journal}

The Journal of Multidisciplinary Healthcare is an international, peerreviewed open-access journal that aims to represent and publish research in healthcare areas delivered by practitioners of different disciplines. This includes studies and reviews conducted by multidisciplinary teams as well as research which evaluates the results or conduct of such teams or healthcare processes in general. The journal covers a very wide range of areas and welcomes submissions from practitioners at all levels, from all over the world. The manuscript management system is completely online and includes a very quick and fair peer-review system. Visit http://www.dovepress.com/testimonials. php to read real quotes from published authors. 